\title{
Individual differences in the effectiveness of self- distancing for young children's emotion regulation
}

\author{
Amanda Grenell ${ }^{1 *}$ D, Emily O. Prager', Catherine Schaefer², \\ Ethan Kross ${ }^{3}$, Angela L. Duckworth ${ }^{4}$ and Stephanie M. Carlson' \\ 'Institute of Child Development, University of Minnesota-Twin Cities, Minneapolis, \\ Minnesota, USA \\ ${ }^{2}$ Pennsylvania State University, University Park, Pennsylvania, USA \\ ${ }^{3}$ University of Michigan, Ann Arbor, Michigan, USA \\ ${ }^{4}$ University of Pennsylvania, Philadelphia, Pennsylvania, USA
}

\begin{abstract}
Self-distancing has been shown to improve children's self-regulation in a variety of tasks. However, it is unknown whether this strategy is more effective for some children than others. This study investigated self-distancing in relation to individual differences in executive function (EF) and effortful control (EC). Typically developing 4- $(n=72)$ and 6year-olds $(n=67)$ were randomly assigned to think about the self from one of four perspectives: self-immersed, control, third-person, or competent media character. Children participated in a frustrating task for up to $10 \mathrm{~min}$ and overt expressions of frustration were coded. Conceptually replicating prior research with adults, younger children, and children with lower EF and lower EC (independent of age) benefitted the most from self-distancing. This suggests self-distancing is especially effective during a frustrating task for children with less developed self-control, adding to a growing body of research showing self-distancing is especially effective for vulnerable individuals.
\end{abstract}

\section{Statement of contribution}

What is already known on this subject?

- Using third-person speech and pretending to be a media character improve children's self-regulation.

- Age and theory of mind skills are related to the effectiveness of self-distancing.

What does this study add?

- Self-distancing can help children regulate their emotions during an emotionally charged task.

- Individual differences in executive function and effortful control are related to the efficacy of self-distancing.

Self-regulation - aligning one's thoughts, feelings, and behaviours with one's goals predicts school readiness and academic success, as well as later life outcomes including health and wealth in adulthood (Duckworth \& Carlson, 2013; Moffitt et al., 2011). Selfregulation includes skills such as executive function (EF), emotion regulation, delay of gratification, and persistence as well as temperament characteristics such as effortful control (EC). Studying self-regulation in preschool and early school-aged children is

*Correspondence should be addressed to Amanda Grenell, Institute of Child Development, University of Minnesota-Twin Cities, 5 I East River Road, Minneapolis, MN 55455, USA (email: grene006@umn.edu). 
important given these abilities develop rapidly during this time (Carlson, Zelazo, \& Faja, 2013). Moreover, when children start school, they are tasked with learning how to regulate themselves in new contexts such as the classroom and playground. In fact, experience attending school is associated with better EF skills (Burrage et al., 2008).

One strategy for improving self-regulation in adults is self-distancing, that is thinking about oneself or one's feelings about a situation from an outsider's perspective (Kross \& Ayduk, 2017). It is one type of psychological distancing, which involves creating mental space between a stimulus and response and is thought to allow the individual to take a step back from the current problem and gain self-control (Liberman \& Trope, 2014; Sigel, 1970). Self-distancing is different from distraction because it involves individuals focusing and reflecting on their feelings, thoughts, or behaviours in a different way instead of avoiding them (Kross \& Ayduk, 2008). The self-distancing paradigm with adults asks them to recall a distressing emotional experience and to listen to verbal instructions to reflect on the event either from their own point of view (self-immersed) or as if they were a fly on the wall (self-distanced; Kross \& Ayduk, 2017). The main finding from studies using this paradigm is that a distanced perspective allowed adults to focus on $w h y$ they were feeling what they were feeling instead of getting stuck on bow they were feeling, resulting in better coping (Kross \& Ayduk, 2011; Kross, Ayduk, \& Mischel, 2005). Recent studies show these effects on emotion regulation generalize to older elementary school children and adolescents (Kross, Duckworth, Ayduk, Tsukayama, \& Mischel, 2011; White, Kross, \& Duckworth, 2015).

Recently, researchers modified the adult self-distancing paradigm for younger children (White \& Carlson, 2015; White et al., 2017). Self-distancing is manipulated by instructing children to think about themselves during the task either from a third-person perspective (self-talk using their name) or from the perspective of someone else entirely by pretending to be an exemplary media character (e.g., Batman). Having children use role-play to adopt the perspective of a media character creates the greatest distance from the self and utilizes children's enjoyment of pretense (Singer \& Singer, 1990). To help children remember their assigned perspective during the task, children received verbal reminders of their perspectives either from an experimenter in the room or from an audio prompt when the experimenter was not present (White \& Carlson, 2015; White et al., 2017). Previous research using this modified paradigm showed preschoolers and early school-aged children performed better on an EF task (White \& Carlson, 2015) and persisted longer on a boring task (White et al., 2017) as distance from the self increased (first-person<thirdperson $<$ media character). Therefore, self-distancing improves children's self-regulation in different contexts. However, an unanswered question is for whom self-distancing works best.

Few studies have examined individual differences in the effectiveness of selfdistancing in children. So far, age has been the most studied factor (White \& Carlson, 2015; White et al., 2017). One study found an age effect for the efficacy of self-distancing with 5year-olds benefiting more than 3-year-olds (White \& Carlson, 2015). This could be because older children have the cognitive skills to take a more distanced perspective, which younger children lack.

Previous individual differences research with adults showed individuals who are more prone to using negative strategies for coping with past emotionally negative experiences (e.g., rumination) benefit more from self-distancing (Kross \& Ayduk, 2009; Kross, Gard, Deldin, Clifton, \& Ayduk, 2012; Kross et al., 2017; Penner et al., 2016; Pfeiler, Wenzel, Weber, \& Kubiak, 2017). For instance, the more symptoms of depression individuals had, the more useful they found self-distancing (Kross et al., 2012). Collectively, this work 
suggests self-distancing may be most effective for vulnerable individuals who are likely to experience more distress and have more negative affect to regulate. However, whether this is true of children is unknown. We address this issue by examining how individual differences in children's baseline level of self-regulation (EF and EC) relate to the efficacy of self-distancing during a frustrating task.

Executive function is 'the set of neurocognitive skills involved in goal-directed problem solving, including working memory, inhibitory control, and set shifting/ flexibility' (Carlson et al., 2013, p. 706). EC is 'the efficiency of executive attention, including the ability to inhibit a dominant response, to activate a subdominant response, to plan, and to detect errors' (Rothbart \& Bates, 2006, p. 129). EF and EC are both aspects of self-regulation. However, EC is usually assessed via surveys, is studied more in emotional contexts, and originated in the field of temperament with a focus on individual differences (Zhou, Chen, \& Main, 2012). EF is usually measured with direct performance, is studied in less emotional contexts, and stems from a developmental cognitive neuroscience perspective (Carlson et al., 2013). In the current study, we explored two possible roles a child's EF and EC might play when using self-distancing in an emotional context.

The first possibility is self-distancing would be more effective for children with higher EF/EC. To use self-distancing effectively, children need to have the cognitive skills to create distance from the self and adopt another perspective, such as EF and theory of mind (ToM). Both of these skills increase with age over the preschool and early school years and are significantly intercorrelated (Carlson \& Moses, 2001; Wellman, Cross, \& Watson, 2001). This possibility is consistent with previous research suggesting children with higher EF benefit more from a ToM intervention, presumably because they already have the skills necessary for them to get the most out of it (Benson, Sabbagh, Carlson, \& Zelazo, 2013). Also, White and Carlson (2015) reported children with higher ToM benefitted more from self-distancing than those with lower ToM. These skills would help children take on a third-person or exemplar perspective, leading them to better utilize selfdistancing. These reports suggest children with higher EF/EC might be better equipped to use a self-distancing strategy during a frustrating task.

The second, opposite possibility is children with lower EF/EC would benefit more from self-distancing. In a frustration task, children with low self-regulation might feel more frustrated than children with high self-regulation before introducing self-distancing. This idea is supported by previous research showing a positive relation between preschoolers' emotion regulation and EF and EC (Carlson \& Wang, 2007; Eisenberg \& Sulik, 2012). Additionally, children who start with lower EF tend to make the most gains after EF interventions because they have more room to grow (Diamond \& Ling, 2016). This hypothesis is also consistent with findings described earlier showing more vulnerable adults benefitted more from self-distancing (e.g., Kross et al., 2012). By examining how EF and EC relate to the effectiveness of self-distancing, we can better understand how to develop more targeted and personalized self-regulation interventions.

To examine whether individual differences in EF and EC moderate the effectiveness of self-distancing, the current study used a frustrating task. Given most of the adult work has used self-distancing to improve emotion regulation, this was a good context to begin exploring this question. Moreover, studies using other types of psychological distancing to improve children's performance on 'hot' self-regulation tasks suggest self-distancing may be particularly promising in emotional contexts. Some of these studies created distance between the child and a tempting stimulus (e.g., marshmallow) by having the child cognitively transform it into something less appealing and more abstract (e.g., 
clouds) or by replacing the treats with abstract symbols (Apperly \& Carroll, 2009; Carlson, Davis, \& Leach, 2005; Mischel \& Baker, 1975). Other studies created social distance by asking children to make decisions to delay gratification (or not) from a third-person perspective instead of from a first-person perspective or by thinking about someone who would be good at the task (e.g., Superman) (Prencipe \& Zelazo, 2005; Karniol et al., 2011). In each case, creating distance from the stimuli or the self resulted in greater selfcontrol. Previous research with adults suggests self-distancing should improve young children's emotion regulation during a frustrating task and the current study allowed us to investigate how individual differences in self-regulation might moderate its effectiveness.

\section{Overview and hypotheses}

In the current study, 4- and 6-year-olds tried to open a locked, transparent box with a toy inside using a set of keys that, unbeknownst to the child, did not contain the key that would open the box (Goldsmith, Reilly, Lemery, Longley, \& Prescott, 1999). Children were randomly assigned to one of four groups based on the modified self-distancing paradigm used in prior research: self-immersed, control, third person, or exemplar (media character) (White \& Carlson, 2015; White et al., 2017). During the frustration task, children in the experimental groups were asked to think about how they were feeling from their assigned perspective. Children in the control group were not instructed to think about their feelings. The task was coded for time spent attempting to unlock the box, overt expressions of frustration, and self-talk.

Given emotion regulation skills and persistence improve with age, we predicted 6year-olds would be less frustrated and work longer on the task than 4-year-olds across conditions. Following prior research (White \& Carlson, 2015; White et al., 2017), we predicted as distance from the self increases (self-immersed $<$ control $<$ third person $<$ exemplar), children in both age groups would show less frustration. After examining the general effectiveness of self-distancing in an emotional context, we explored competing hypotheses for the moderating role of individual differences in self-regulation for the efficacy of self-distancing.

\section{Method}

\section{Participants}

Typically developing children $(N=139)$ participated: 72 4-year-olds (35 girls, $M=47.83$ months, $S D=0.56)$ and 67 6-year-olds $(36$ girls, $M=71.75$ months, $S D=0.56$ ). A power analysis based on previous research indicated 32 children were needed in each condition to have sufficient power to detect significant differences between groups $(N=128)$. Most of the sample was Caucasian, non-Hispanic (85.6\%), but some participants identified as Asian (.7\%), African-American (0.7\%), White-Hispanic (6.5\%), and biracial (5.8\%). One caregiver ( $0.7 \%)$ chose not to report ethnicity. Most of the sample was upper-middle class (median family income of \$100,000-125,000) with 10.8\% earning \$50,000 or less, 32.4\% earning \$50,000-\$100,000, 29.5\% earning \$100,000$\$ 150,000$, and $23.8 \%$ earning more than \$150,000 annually. Five families (3.6\%) did not report income level.

Children were recruited using a university participant database in a metropolitan area in the Midwest region of the United States, and this study gained approval from the Institutional Review Board of the same University. Parents were compensated \$10, and children received 
a small toy and T-shirt. Children were randomly assigned to one of four conditions: selfimmersed $(n=34)$, control $(n=34)$, third person $(n=33)$, or exemplar $(n=38)$.

Twenty-nine additional children participated but were later excluded due to experimenter error (3), video/technical errors (12), caregiver interference (3), children being too upset to finish the task (6), child not understanding the task (1), a bathroom break during the target task (2), or having prior experience with the target task (2).

\section{Procedure}

Children were individually assessed in the laboratory during a 60-min session. They first completed baseline EF measures. Next, they participated in the frustration task and lastly completed a verbal ability control task. A female experimenter administered all tasks.

\section{Measures}

Child tasks

See Table 1 for descriptive data.

Forward and backward digit span (Davis \& Pratt, 1996)

Children had to repeat a sequence of numbers stated by the experimenter starting with two digits and increasing by one digit if the child correctly recited the sequence. Children were then asked to recite sequences of numbers in reverse order. Again, the task began with two digits and increased by one digit with each correct trial. Scores corresponded to the highest number of digits recalled on each task.

Dimensional change card sort task (DCCS) - NIH toolbox cognition battery (Zelazo et al., 20I3) This was used as a baseline measure of EF. Children were asked to sort objects on a 15" laptop computer screen by shape (e.g., trucks in one box and balls in another box) and then by colour (e.g., yellow objects in one box and blue objects in another box) by pressing one of two arrows marked on the keyboard. Then, they played the shape and colour game together in mixed trials. Reaction time and accuracy scores were combined to create a total score (possible range $=0-10$ ).

Flanker - NIH toolbox cognition battery (Zelazo et al., 2013)

This computerized task was used as another EF baseline measure. Children saw a row of five fish. Each fish had an arrow inside of it pointing to the left or right. Children were told to press the button on the keyboard that matched the way the middle fish was pointing. The task included congruent trials (when all the fish pointed the same way) and incongruent trials (when the middle fish pointed a different way). Reaction time and accuracy scores were combined to create a total score (possible range $=0-10$ ).

Locked box (Goldsmith et al., 1999)

The frustrating task is from the preschool version of the Laboratory Temperament Assessment Battery (Lab-TAB). After children selected a desirable toy (e.g., doll or remote control car), the experimenter demonstrated how to use a set of keys to unlock a 
Table I. Descriptive data for study tasks

\begin{tabular}{|c|c|c|c|c|c|}
\hline Task & $N$ & $\begin{array}{l}\text { Observed } \\
\text { range }\end{array}$ & Theoretical range & M & $S D$ \\
\hline Forward digit span & 137 & $2-8$ & $\begin{array}{l}\text { I - highest number of digits } \\
\text { child could recall }\end{array}$ & 4.59 & 0.92 \\
\hline Backward digit span & 137 & $0-6$ & $\begin{array}{l}\text { I - highest number of digits } \\
\text { child could recall }\end{array}$ & 2.19 & 1.03 \\
\hline $\begin{array}{l}\text { Dimensional change } \\
\text { card sort task (DCCS) }\end{array}$ & 125 & $0-8.79$ & $0-10$ & 4.07 & 1.52 \\
\hline Flanker task & 132 & $0-8.89$ & $0-10$ & 5.66 & 1.76 \\
\hline Global frustration & 139 & $\mathrm{I}-3$ & $\mathrm{I}-3$ & 1.53 & 0.68 \\
\hline Total time on task & 139 & $45-600$ & $\mathrm{I}-600 \mathrm{~s}$ & 355.10 & 203.38 \\
\hline $\begin{array}{l}\text { Peabody picture } \\
\text { vocabulary Test-IV }\end{array}$ & 135 & $80-145$ & $0-160$ & 119.77 & 12.44 \\
\hline First-person speech use & 138 & $0-23$ & $\begin{array}{l}0 \text { - highest frequency of } \\
\text { first-person speech }\end{array}$ & 2.06 & 4.06 \\
\hline Third-person speech use & 138 & $0-3$ & $\begin{array}{l}0 \text { - highest frequency of } \\
\text { third-person speech }\end{array}$ & 0.06 & 0.31 \\
\hline Exemplar speech use & 138 & $0-12$ & $\begin{array}{l}0 \text { - highest frequency of } \\
\text { exemplar speech }\end{array}$ & 0.30 & 1.63 \\
\hline
\end{tabular}

transparent box. Children were given a turn to open the lock with the key and given help as needed. Next, the toy was placed inside the transparent box and locked, with the experimenter explaining, 'Okay, now we have to leave it in the box while we play our other games'. The transparent box was set aside while the child completed the EF measures. When the box was presented again later, children were told if they could find the correct key to unlock the box, they could play with the toy inside. The experimenter said they could stop trying to open the box any time they wanted by placing the keys on a designated table across the room. After rule checks to ensure children remembered how to retrieve the toy (i.e., find the right key to unlock the box) and what they should do if they were done trying (i.e., put the keys on the table), they were given a set of keys they believed included the key that would unlock the box. In reality, the experimenter secretly swapped the set of keys so none of the keys worked. The experimenter then left 'to do some work' in another room and children worked on the task for 10 min or until they indicated they were finished trying.

Manipulations. After explaining the instructions for the Locked Box task, the experimenter warned children that 'it can be frustrating sometimes trying all these keys' and suggested a strategy to use when they got frustrated during the task depending on their experimental condition. Children in the self-immersed condition were told to ask themselves, 'How am I feeling?' Children in the third-person condition were told to ask themselves, 'How is [child's name] feeling?' Children in the exemplar condition were asked to pretend to be a popular media character of their choosing (Rapunzel, Bob the Builder, Batman, or Dora the Explorer) and were given a prop associated with the character (tiara, tool belt, black cape, or backpack, respectively). Then children were told to think about how that character was feeling (e.g., 'How is [Batman] feeling?'). Children in the control condition were not instructed to think about their feelings during the task. 
Testing phase. Children were left alone to work on the Locked Box task for 10 min or until they were done trying. To help children in the experimental conditions remember their self-distancing strategy, an audio recording on a computer in the room repeated the phrase to say to themselves when they got frustrated (e.g., 'How is Batman feeling?') in a female voice once every minute. No audio prompts were used in the control condition.

Peabody picture vocabulary Test-IV (Dunn \& Dunn, 2007)

Given past research has found a correlation between verbal ability and $\mathrm{EF}$, we included this standardized measure of receptive vocabulary to control for verbal ability. Children were shown sets of four different pictures and, for each set, were asked to point to the picture matching the word the experimenter said aloud. Starting level was determined by age and the task continued until they got eight of 12 words incorrect in one section. Standardized scores were used in analyses.

\section{Parent questionnaires}

Children's Behaviour Questionnaire (CBQ) - very short form (Putnam \& Rothbart, 2006)

Parents rated how true statements were about their child's temperament in a variety of situations and contexts. A composite score for the Effortful Control subscale was calculated.

\section{Locked box task coding}

Videos were coded for time on task, frustration, and use of self-speech. Time on task was the total amount of time (in seconds) the child spent working to unlock the box, beginning when the experimenter left the room and ending after $10 \mathrm{~min}(600 \mathrm{~s})$ or when children indicated they were finished (i.e., by putting the keys on the designated table). Children's self-speech during the frustrating task was coded for frequency of first-person, third-person, and exemplar speech.

Frustration was rated globally on a scale from 1 to 3 and was determined by the degree of overt frustration and coping children demonstrated while working on the task as follows: 1 = child showed no outward signs of frustration, few negative facial expressions, and had minimal negative self-talk throughout the task; $2=$ child occasionally had outbursts of negative emotions but was able to calm him/herself; $3=$ child had frequent outbursts of negative emotions and was unable to calm him/herself while working on the task (see Appendix). Seventy-six percent of the videos were double-coded for task time by a coder who was blind to the hypotheses and showed good reliability, ICC (105) $=.99$. Seventy-three percent of the videos were double-coded for the global frustration rating by two coders who were blind to the hypotheses and showed good reliability, ICC $(102)=.78$. Disagreements were discussed and resolved.

\section{Results}

\section{General effects of self-distancing}

First, we tested the effects of self-distancing on time on task and global frustration. Children's frustration rating and time on task were significantly correlated, $r(139)=.30$, $p<.005$. Children got more frustrated the longer they worked on the task. Given these two variables were correlated, it was necessary to covary them in analyses to better 
understand whether effects were due to distancing itself, independent of how long children worked on the task.

Time on task

A 2(age: 4- and 6-year-olds) $\times 4$ (condition: immersed, control, third person, exemplar) ANCOVA using time on task as the dependent variable and controlling for global frustration rating revealed a significant main effect of age. Across conditions, 6-year-olds worked significantly longer on the task $(M=433.49 \mathrm{~s}, S D=183.78 \mathrm{~s})$ than 4-year-olds $(M=282.15 \mathrm{~s}, S D=194.44 \mathrm{~s}), F(1,130)=20.28, p<.0005, \eta_{p}^{2}=.14$. We found no main effect of condition or an age $\times$ condition interaction.

\section{Global frustration rating}

To test the effects of self-distancing on emotion regulation, we used a 2(age: 4- and 6-yearolds $) \times 4$ (condition: immersed, control, third person, exemplar) ANCOVA using global frustration as the dependent variable and controlling for time on task. There was no main effect of age or condition. However, age interacted significantly with condition, $F(3,130)=3.08, p=.03, \eta_{p}^{2}=.07$. There was a main effect of condition for 4-year-olds, $F(3,67)=3.24, p=.03, \eta_{p}^{2}=.13$, but not 6-year-olds, $F(3,62)=.90, p=.45$. Planned contrasts showed 4-year-olds in the self-immersed condition were significantly more frustrated $(M=1.88, S D=0.70)$ than those in the exemplar condition $(M=1.33$, $S D=0.66), p=.02$, and those in the control condition $(M=1.24, S D=0.56), p=.004$. Four-year-olds in the self-immersed condition $(M=1.88, S D=0.70)$ were also marginally more frustrated than children in the third-person condition $(M=1.47, S D=0.72), p=.11$.

A follow-up linear trend analysis revealed 4-year-olds became marginally less frustrated as distance from the self increased, $p=.08$. There were no significant condition differences for 6-year-olds (Figure 1).

\section{Individual differences in the effectiveness of self-distancing}

Executive function

We next examined how children's baseline EF was related to the effectiveness of selfdistancing. Given all four EF tasks (FDS, BDS, DCCS, and Flanker) were correlated

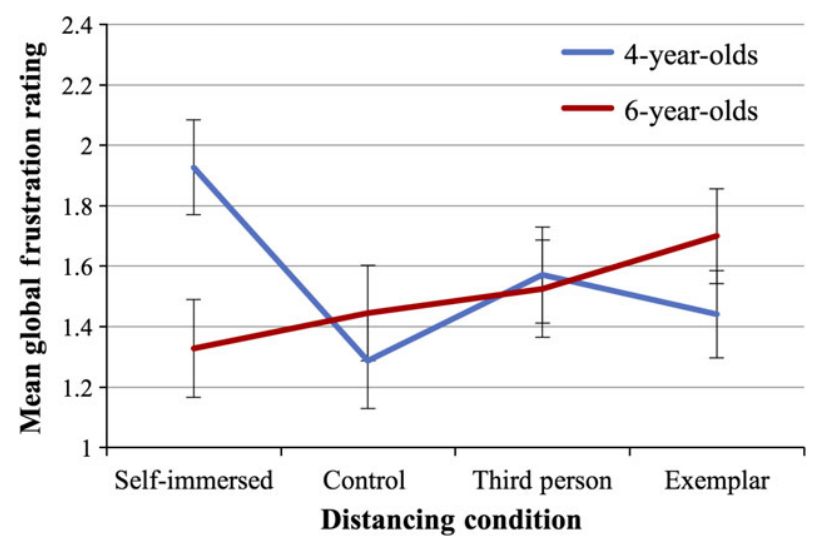

Figure I. Age $\times$ condition interaction controlling for time on task (in seconds). Bars represent standard error of the mean. [Colour figure can be viewed at wileyonlinelibrary.com] 


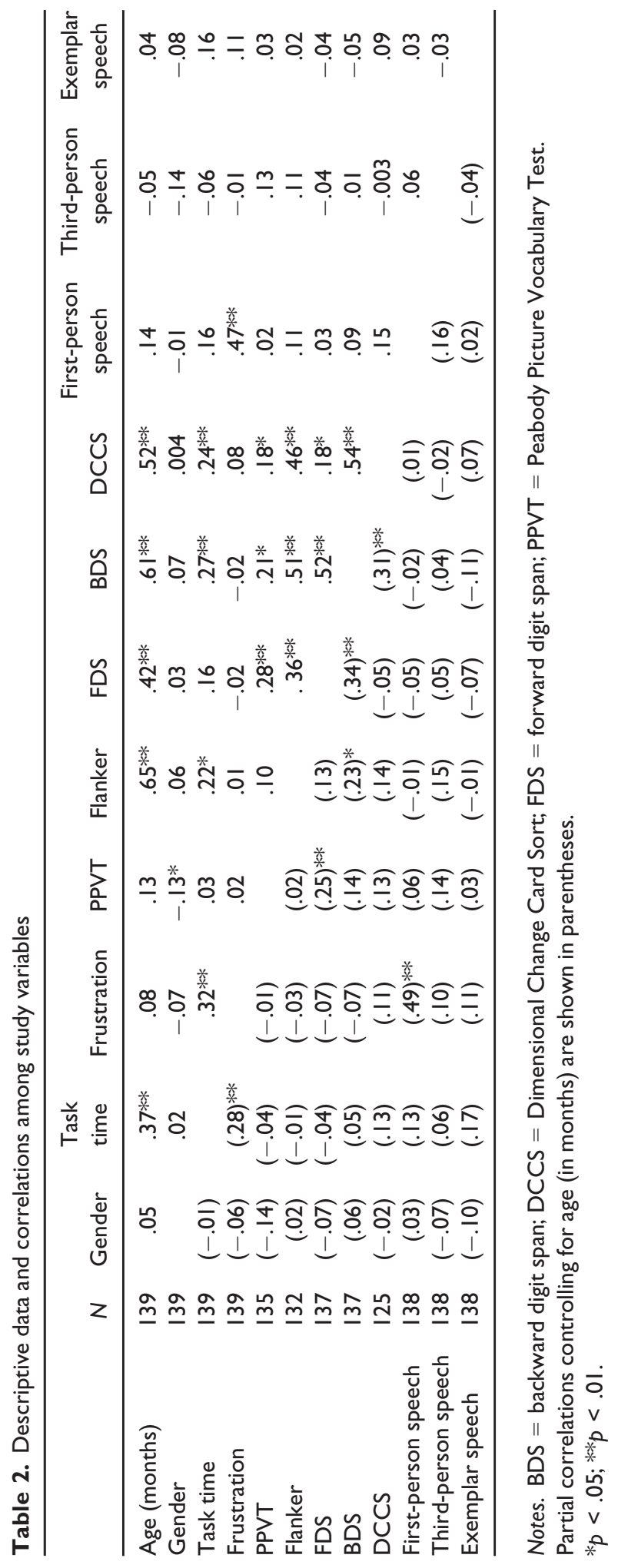


(Table 2), a composite EF score was created by averaging the standardized scores on all tasks. If children were missing an EF task $(n=22)$, averages by age for that task were used. A median split on composite EF scores was then used to create high and low EF groups. Given these measures of EF were significantly correlated with both age and verbal ability (PPVT), age in months and PPVT standard scores were included as covariates.

A 2(EF: low, high) $\times 4$ (condition: immersed, control, third person, and exemplar) ANCOVA with global frustration as the dependent variable controlling for age in months, PPVT scores, and time on task revealed no main effect of condition, $p=.36$, or EF level, $p=.30$. There was a significant $\mathrm{EF}$ level $\times$ condition interaction; however, $F(3,124)=$ $3.13, p=.03, \eta_{p}^{2}=.07$. Planned contrasts revealed a significant main effect of condition for low EF children, $F(3,60)=3.33, p=.03, \eta_{p}^{2}=.14$. Low EF children were significantly more frustrated in the self-immersed condition $(M=1.94, S D=0.68)$ than in the exemplar condition $(M=1.39, S D=0.70), p=.02$, and the control condition $(M=1.21, S D=0.58), p=.004$. Low $\mathrm{EF}$ children in the self-immersed condition $(M=1.94, S D=0.68)$ were also marginally more frustrated than low EF children in the third-person condition $(M=1.50, S D=0.76), p=.07)$. There were no other significant differences between conditions for low EF children. For high EF children, there was no main effect of condition, $p=.56$. Linear trend analyses revealed a marginal linear trend for low EF children, $p=.08$, but not high EF children, $p=.19$ (Figure 2).

\section{Effortful control}

The EC subscale of the CBQ was used as a parent-reported measure of individual differences in EC. A median split on EC scores was used to create high and low EC groups. Age in months was significantly correlated with EC, $r(131)=.19, p=.03$, and 6-year-olds had significantly higher EC scores than 4-year-olds, $F(1,129)=4.47$, $p=.04, \eta_{p}^{2}=.03$. Therefore, we also controlled for age in months in the following analyses.

A 2(EC: low, high) $\times 4$ (condition: immersed, control, third person, exemplar) ANCOVA with global frustration as the dependent measure controlling for time on

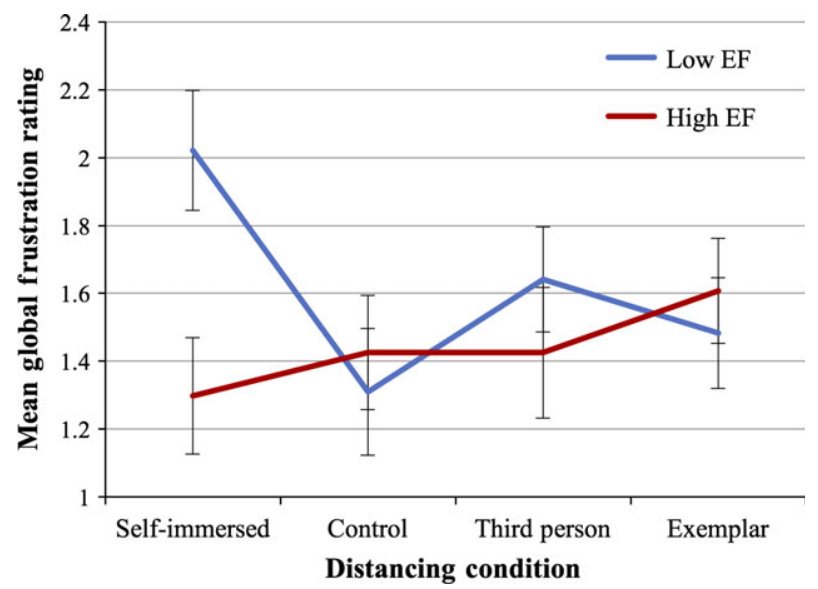

Figure 2. Condition by EF level interaction controlling for age in months, verbal ability (Peabody Picture Vocabulary Test Scores), and time on task (in seconds). Bars represent standard error of the mean. [Colour figure can be viewed at wileyonlinelibrary.com] 
task and age in months revealed no significant main effect of condition, $F(3,121)=1.55, p=.21$, or of $\mathrm{EC}, F(1,121)=.05, p=.83$. However, there was a marginally significant interaction between EC and self-distancing condition, $F(3,121)=2.57, p=.057, \eta_{p}^{2}=.06$ (Figure 3). Planned contrasts revealed a significant main effect of condition for low EC children, $F(3,66)=3.01, p=.04$, $\eta_{p}^{2}=.12$. Low EC children in the self-immersed condition $(M=1.94, S D=0.64)$ were significantly more frustrated than children in the control condition $(M=1.35$, $S D=0.61), p=.008$, the third-person condition $(M=1.38, S D=0.62), p=.02$, and the exemplar condition $(M=1.43, S D=0.60), p=.03$. There were no other significant differences between conditions for low EC children. For high EC children, there were no significant differences in frustration levels across conditions, $p=.24$. A linear trend analysis revealed a marginal linear trend for low EC children, $p=.056$, but not for high EC children, $p=.27$.

\section{Self-speech}

Most children (78\%) correctly recalled their assigned distancing prompt (e.g., 'How am I feeling?') when asked by the experimenter after the frustration task. Although children were not directed to implement their distancing prompt aloud, we nevertheless observed many children $(n=86)$ talk aloud spontaneously during the frustration task. Thus, we coded children's use of first-person, third-person, and exemplar (e.g., 'Batman feels...') speech and performed exploratory analyses to see whether the frequency of self-speech was related to children's performance during the frustration task and to the effectiveness of self-distancing. The means for each type of speech across conditions by age are presented in Table 3. Due to low frequencies of third-person and exemplar speech, only first-person speech was examined further.

A 2(first-person speech use: yes, no) $\times 4$ (condition: immersed, control, third person, exemplar) ANCOVA with global frustration as the dependent variable controlling for time on task revealed a significant main effect of first-person speech on frustration ratings,

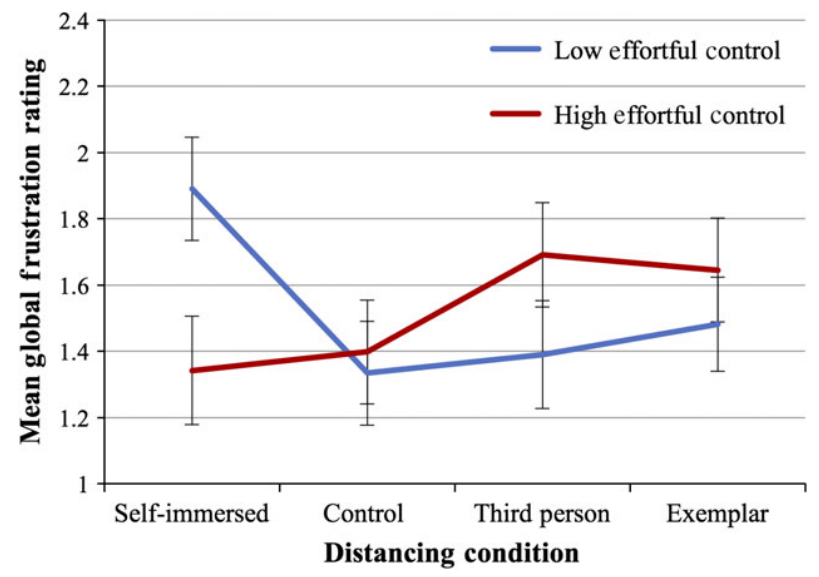

Figure 3. Condition $x$ effortful control level interaction controlling for time on task (in seconds) and age in months. Bars represent standard error of the mean. [Colour figure can be viewed at wileyonlinelibrary.com] 
Table 3. Mean frequencies of self-speech by condition and age

\begin{tabular}{llcccc}
\hline Age group & $\begin{array}{c}\text { Type of } \\
\text { self-speech }\end{array}$ & $\begin{array}{c}\text { Self-immersed } \\
\text { condition }\end{array}$ & $\begin{array}{c}\text { Control } \\
\text { condition }\end{array}$ & $\begin{array}{c}\text { Third-person } \\
\text { condition }\end{array}$ & $\begin{array}{c}\text { Exemplar } \\
\text { condition }\end{array}$ \\
\hline 4-year-olds & First person & $2.4 \mathrm{I}(2.53)$ & $0.29(0.59)$ & $2.06(4.74)$ & $1.33(2.73)$ \\
& Third person & $0.00(0.00)$ & $0.00(0.00)$ & $0.24(0.75)$ & $0.05(0.22)$ \\
& Exemplar & $0.00(0.00)$ & $0.00(0.00)$ & $0.00(0.00)$ & $0.81(2.62)$ \\
6-year-olds & First person & $2.59(5.84)$ & $3.31(5.06)$ & $2.13(4.98)$ & $2.59(3.86)$ \\
& Third person & $0.00(0.00)$ & $0.13(0.34)$ & $0.00(0.00)$ & $0.06(0.24)$ \\
& Exemplar & $0.00(0.00)$ & $0.00(0.00)$ & $0.00(0.00)$ & $1.41(3.47)$ \\
\hline
\end{tabular}

Note. Standard deviations appear in parentheses.

$F(1,128)=41.61, p<.005, \eta_{p}^{2}=.25$. Children who used first-person speech were significantly more frustrated $(M=1.90, S D=0.74)$ than children who $\operatorname{did} \operatorname{not}(M=1.25$, $S D=0.49)$. There were no other significant main effects or interactions.

\section{Discussion}

The current study examined individual differences in the effectiveness of self-distancing in an emotional context. Three central findings emerged.

First, age influenced the effectiveness of distancing on emotion regulation. Younger children were least frustrated in the most distanced condition (i.e., exemplar), whereas there were no significant differences in frustration across conditions for older children. This finding went against our hypothesis that older children would benefit more from distancing due to having more developed cognitive skills such as EF and ToM. The only other study finding an age effect for the efficacy of self-distancing was with 3-and 5-yearolds (White \& Carlson, 2015), whereas we tested 4- and 6-year-olds. White et al. (2017) tested 4- and 6-year-olds (using a boring persistence task) and found self-distancing to be equally effective at both ages. A tentative conclusion across these three studies is that children benefit from this strategy beginning around 4 years, when they have sufficient ToM to get into character (White \& Carlson, 2015). That said, we do not know why 6-yearolds in the present study did not benefit from distancing. It is possible the effects are taskdependent. The task used in White and Carlson (2015) (Minnesota Executive Function Scale) was adaptive, ensuring it was equally challenging to both younger and older participants and allowing for sufficient variability in children's performance. In contrast, the Locked Box task used in the current study did not adapt depending on how the child reacted emotionally during the task and might not have elicited enough frustration overall. Thus, task type must be taken into account when examining the effects of self-distancing in future research.

Second, and relatedly, the efficacy of self-distancing in an emotional context depended on children's baseline level of self-regulation. Children with low EF and EC who were asked to pretend to be someone else were significantly less frustrated than those who were asked to think about their own feelings. This pattern was not found for children with relatively high EF or EC. Older children, or those with more well-developed EF regardless of age, could be using other emotion regulation strategies, not needing to rely on selfdistancing during the task. Previous research demonstrates young children's use and understanding of emotion regulation strategies increases with age during the preschool 
and early school years (e.g., Brenner \& Salovey,1997; Cole, Dennis, Smith-Simon, \& Cohen, 2009; Eisenberg \& Sulik, 2012). These findings are also consistent with research showing children who start lower in EF show the greatest gains from EF interventions (Diamond \& Ling, 2016) and research with adults suggesting more vulnerable individuals benefit more from self-distancing (e.g., Kross et al., 2012).

Third, children's use of first-person speech was related to their frustration during the task. Across conditions, age groups, and self-regulation levels, children's use of spontaneous first-person speech was significantly positively correlated with their global frustration, even when controlling for time on task. This demonstrates that a selfimmersed perspective is detrimental to emotion regulation, consistent with previous research with adults (Kross et al., 2005), and the first evidence of this effect in young children to our knowledge. It also highlights the need to study children's overt speech during emotion regulation tasks as a window into self-control (Kross et al., 2014; Moser et al., 2017).

\section{Limitations and future directions}

The present study has notable limitations. One unforeseen confound was the fact that the control group did not hear audio reminders during the Locked Box task. Anecdotally, the audio reminders (e.g., 'How is [child's name] feeling?') added to the frustration for children in the experimental conditions, with some getting annoyed that the computer was talking to them. Although there were no statistically significant differences in frustration between the control and experimental groups across age groups, there was a significant difference between the control and self-immersed conditions for 4-year-olds, with those in the self-immersed condition being more frustrated. This suggests the audio reminders themselves contributed to children's frustration levels, thus potentially limiting the benefits of distancing when compared with a control group without this added frustration.

Another limitation is not knowing how children were using the self-distancing strategy. One concern is children may have used the distancing instructions to engage in distraction instead of adopting a different mindset. Most children (78\%) remembered the distancing prompt they were supposed to be asking themselves (e.g., 'How is Batman feeling?') during the Locked Box task, suggesting they were keeping it in mind. Although the low frequency of self-speech in the distancing conditions does not allow us to statistically examine the extent to which children used self-speech to talk about their emotions, we have anecdotal evidence this was the case. For example, one 4-year-old who was pretending to be Rapunzel during the task dropped the keys on the table, expressed her frustration, 'Oh my goodness!', touched her tiara, and then spontaneously asked herself, 'How is Rapunzel feeling?' before going back to work on the task. A 6-year-old boy also told the researcher he kept working on the keys because, 'Batman never gets frustrated'. More research is needed to investigate how the distancing instructions affect children's behaviour and self-speech during the task.

Future research should build on the current study to better understand individual differences in the efficacy of self-distancing in young children. For example, researchers could examine additional individual characteristics beyond age and baseline selfregulation (e.g., stress levels, caregiver quality) and compare self-regulation in different contexts (e.g., emotional and non-emotional). Another important future direction is 
conducting training studies to determine whether providing the opportunity to practice self-distancing leads to long-term improvements in self-regulation.

\section{Conclusion}

The current study suggests self-distancing through the use of role-play can be an effective, low-cost strategy to improve emotion regulation, particularly for children with relatively poor self-regulation. In particular, self-distancing could be added to broader socioemotional interventions for children as an adaptive way to reflect upon and process their negative emotions. More research on who benefits most from self-distancing will inform the creation of more personalized and effective interventions.

\section{Acknowledgements}

This research was supported by a grant from the John Templeton Foundation (21564) to ALD, EK, and SMC. We want to thank undergraduate research assistants including Madeline Lee, Sofia Madden, Sarah Lien, and Elsa Mattson and all of the families who participated in the current study.

\section{References}

Apperly, I. A., \& Carroll, D. J. (2009). How do symbols affect 3 to 4 year olds' executive function? Evidence from a reverse-contingency task. Developmental Science, 12, 1070-1082. https://doi. org/10.1111/j.1467-7687.2009.00856.x

Benson, J. E., Sabbagh, M. A., Carlson, S. M., \& Zelazo, P. D. (2013). Individual differences in executive functioning predict preschoolers' improvement from theory-of-mind training. Developmental Psychology, 49, 1615-1627. https://doi.org/10.1037/a0031056

Brenner, E. M., \& Salovey, P. (1997). Emotion regulation during childhood: Developmental, interpersonal, and individual considerations. In P. Salovey \& D. Sluyter (Eds.), Emotional development, and emotional intelligence: Educational implications (pp. 168-192). New York, NY: Basic Books.

Burrage, M. S., Ponitz, C. C., McCready, E. A., Shah, P., Sims, B. C., Jewkes, A. M., \& Morrison, F. J. (2008). Age-and schooling-related effects on executive functions in young children: A natural experiment. Child Neuropsychology, 14, 510-524. https://doi.org/10.1080/092970407017 56917

Carlson, S. M., Davis, A. C., \& Leach, J. G. (2005). Less is more: Executive function and symbolic representation in preschool children. Psychological Science, 16, 609-616. https://doi.org/10. 1111/j.1467-9280.2005.01583.x

Carlson, S. M., \& Moses, L. J. (2001). Individual differences in inhibitory control and children's theory of mind. Child Development, 72, 1032-1053. https://doi.org/10.1111/1467-8624.00333

Carlson, S. M., \& Wang, T. S. (2007). Inhibitory control and emotion regulation in preschool children. Cognitive Development, 22, 489-510. https://doi.org/10.1016/j.cogdev.2007.08.002

Carlson, S. M., Zelazo, P. D., \& Faja, S. (2013). Executive function. In P. D. Zelazo (Ed.), Oxford handbook of developmental psychology, Vol. 1 (pp. 706-743). New York, NY: Oxford University Press.

Cole, P. M., Dennis, T. M., Smith-Simon, K. E., \& Cohen, L. H. (2009). Preschoolers' emotion regulation strategy understanding: Relation with emotion socialization and child self-regulation. Social Development, 18, 324-352. https://doi.org/10.1111/j.1467-9507.2008.00503.x 
Davis, H. L., \& Pratt, C. (1996). The development of children's theory of mind: The working memory explanation. Australian Journal of Psychology, 47, 25-31. https://doi.org/10.1080/ 00049539508258765

Diamond, A., \& Ling, D. S. (2016). Conclusions about interventions, programs, and approaches for improving executive functions that appear justified and those that, despite much hype, do not. Developmental Cognitive Neuroscience, 18, 34-48. https://doi.org/10.1016/j.dcn.2015.11. 005

Duckworth, A. L., \& Carlson, S. M. (2013). Self-regulation and school success. In B. W. Sokol, F. M. E. Grouzet \& U. Müller (Eds.), Self-regulation and autonomy: Social and developmental dimensions of human conduct (pp. 208-230). New York, NY: Cambridge University Press.

Dunn, L. M., \& Dunn, D. M. (2007). Peabody picture vocabulary test (4th ed.). San Antonio, TX: Pearson.

Eisenberg, N., \& Sulik, M. J. (2012). Emotion-related self-regulation in children. Teaching of Psychology, 39, 77-83. https://doi.org/10.1177/0098628311430172

Goldsmith, H. H., Reilly, J., Lemery, K. S., Longley, S., \& Prescott, A. (1999). The laboratory temperament assessment battery: Preschool version. Madison, WI: University of Wisconsin.

Karniol, R., Galili, L., Shtilerman, D., Naim, R., Stern, K., Manjoch, H., \& Silverman, R. (2011). Why Superman can wait: Cognitive self-transformation in the delay of gratification paradigm. Journal of Clinical Child \& Adolescent Psychology, 40, 307-317. https://doi.org/10.1080/15374416. 2011.546040

Kross, E., \& Ayduk, O. (2008). Facilitating adaptive emotional analysis: Distinguishing distancedanalysis of depressive experiences from immersed-analysis and distraction. Personality and Social Psychology Bulletin, 34, 924-938. https://doi.org/10.1177/0146167208315938

Kross, E., \& Ayduk, O. (2009). Boundary conditions and buffering effects: Does depressive symptomology moderate the effectiveness of self-distancing for facilitating adaptive emotional analysis? Journal of Research in Personality, 43, 923-927. https://doi.org/10.1016/j.jrp.2009. 04.004

Kross, E., \& Ayduk, O. (2011). Making meaning out of negative experiences by self-distancing. Current Directions in Psychological Science, 20, 187-191. https://doi.org/10.1177/ 0963721411408883

Kross, E., \& Ayduk, O. (2017). Self-distancing: Theory, research, and current directions. Advances in Experimental Social Psychology, 55, 81-136. https://doi.org/10.1016/bs.aesp.2016.10.002

Kross, E., Ayduk, O., \& Mischel, W. (2005). When asking "why" does not hurt: Distinguishing rumination from reflective processing of negative emotions. Psychological Science, 16, 709715. https://doi.org/10.1111/j.1467-9280.2005.01600.x

Kross, E., Bruehlman-Senecal, E., Park, J., Burson, A., Dougherty, A., Shablack, H., ... Ayduk, O. (2014). Self-talk as a regulatory mechanism: How you do it matters. Journal of Personality and Social Psychology, 106, 304-324. https://doi.org/10.1037/a0035173

Kross, E., Duckworth, A., Ayduk, O., Tsukayama, E., \& Mischel, W. (2011). The effect of selfdistancing on adaptive versus maladaptive self-reflection in children. Emotion, 11, 1032-1039. https://doi.org/10.1037/a0021787

Kross, E., Gard, D., Deldin, P., Clifton, J., \& Ayduk, O. (2012). "Asking why" from a distance: Its cognitive and emotional consequences for people with major depressive disorder. Journal of Abnormal Psychology, 121, 559-569. https://doi.org/10.1037/a0028808

Kross, E., Vickers, B. D., Orvell, A., Gainsburg, I., Moran, T. P., Boyer, M., . . Ayduk, O. (2017). Thirdperson self-talk reduces Ebola worry and risk perception by enhancing rational thinking. Applied Psychology: Health and Well-Being, 9, 387-409. https://doi.org/10.1111/aphw.12103

Liberman, N., \& Trope, Y. (2014). Traversing psychological distance. Trends in Cognitive Sciences, 18, 364-369. https://doi.org/10.1016/j.tics.2014.03.001

Mischel, W., \& Baker, N. (1975). Cognitive appraisals and transformations in delay behavior. Journal of Personality and Social Psychology, 31, 254-261. https://doi.org/10.1037/h0076272

Moffitt, T. E., Arseneault, L., Belsky, D., Dickson, N., Hancox, R. J., Harrington, H., .. Caspi, A. (2011). A gradient of childhood self-control predicts health, wealth, and public safety. 
Proceedings of the National Academy of Sciences, 108, 2693-2698. https://doi.org/10.1073/ pnas. 1010076108

Moser, J. S., Dougherty, A., Mattson, W. I., Katz, B., Moran, T. P., Guevarra, D., . . Kross, E. (2017). Third-person self-talk facilitates emotion regulation without engaging cognitive control: Converging evidence from ERP and fMRI. Scientific Reports, 7, 1-9. https://doi.org/10.1038/ s41598-017-04047-3

Penner, L. A., Guevarra, D. A., Harper, F. W., Taub, J., Phipps, S., Albrecht, T. L., \& Kross, E. (2016). Self-distancing buffers high trait anxious pediatric cancer caregivers against short-and longerterm distress. Clinical Psychological Science, 4, 629-640. https://doi.org/10.1177/ 2167702615602864

Pfeiler, T. M., Wenzel, M., Weber, H., \& Kubiak, T. (2017). Adaptive modes of rumination: The role of subjective anger. Cognition and Emotion, 31, 580-589. https://doi.org/10.1080/02699931. 2015.1117961

Prencipe, A., \& Zelazo, P. D. (2005). Development of affective decision making for self and other: Evidence for the integration of first-and third-person perspectives. Psychological Science, 16, 501-505. https://doi.org/10.1111/j.0956-7976.2005.01564.x

Putnam, S. P., \& Rothbart, M. K. (2006). Development of short and very short forms of the Children's Behavior Questionnaire. Journal of Personality Assessment, 87, 102-112. https://doi.org/10. 1207/s15327752jpa8701_09

Rothbart, M. K., \& Bates, J. E. (2006). Temperament. In N. Eisenberg, W. Damon \& R. M. Lerner (Eds.), Handbook of child psychology: Vol. 3, Social, emotional, and personality development (6th ed., pp. 99-166). Hoboken, NJ: Wiley.

Sigel, I. (1970). The distancing hypothesis: A causal hypothesis for the acquisition of representational thought. In M. R. Jones (Ed.), Early schooling: The national debate (pp. 129-150). New Haven, CT: Yale University Press.

Singer, D. G., \& Singer, J. L. (1990). The house of make-believe: Children's play and the developing imagination. Cambridge, MA: Harvard University Press.

Wellman, H. M., Cross, D., \& Watson, J. (2001). Meta-analysis of theory-of-mind development: The truth about false belief. Child Development, 72, 655-684. https://doi.org/10.1111/1467-8624. 00304

White, R. E., \& Carlson, S. M. (2015). What would Batman do? Self-distancing improves executive function in young children. Developmental Science, 9, 419-426. https://doi.org/10.1111/desc. 12314

White, R. E., Kross, E., \& Duckworth, A. L. (2015). Spontaneous self-distancing and adaptive selfreflection across adolescence. Child Development, 86, 1272-1281. https://doi.org/10.1111/ cdev. 12370

White, R. E., Prager, E. O., Schaefer, C., Kross, E., Duckworth, A. L., \& Carlson, S. M. (2017). The "Batman effect": Improving perseverance in young children. Child Development, 88, 15631571. https://doi.org/10.1111/cdev.12695

Zelazo, P. D., Anderson, J. E., Richler, J., Wallner-Allen, K., Beaumont, J. L., \& Weintraub, S. (2013). II. NIH toolbox cognition battery (CB): Measuring executive function and attention. Monographs of the Society for Research in Child Development, 78, 16-33. https://doi.org/10.1111/mono. 12032

Zhou, Q., Chen, S. H., \& Main, A. (2012). Commonalities and differences in the research on children's effortful control and executive function: A call for an integrated model of selfregulation. Child Development Perspectives, 6, 112-121. https://doi.org/10.1111/j.1750-8606. 2011.00176.x

Received I/ October 20 I7; revised version received 6 June 2018 


\section{Appendix: Global frustration coding}

Each video of the Locked Box task was coded from the time the experimenter said, 'I'll see you in a bit' to when either the child left the chair to end the task or the experimenter returned (after $10 \mathrm{~min}$ ). Leaving the chair to end the task can happen in order to put the keys on the table, or to leave the room.

Based on the amount of frustration and regulation shown across the entire task, children were given a global frustration score on a scale from 1 to 3 . See the table below for descriptions of what constituted a child receiving a 1,2 , or 3 .

\begin{tabular}{ll}
\hline Global frustration score & Description \\
\hline I & $\begin{array}{c}\text { Child showed no outward signs of frustration, few negative facial } \\
\text { expressions, and had minimal negative self-talk throughout the task } \\
\text { Child occasionally had outbursts of negative emotions but was able to } \\
\text { calm him/herself down } \\
\text { Child had frequent outbursts of negative emotions and was unable to } \\
\text { calm him/herself while working on the task }\end{array}$ \\
\hline
\end{tabular}

In order to rate a child on the global frustration scale, coders paid attention to the frequency of the following overt displays of frustration:

Verbal frustration: verbal negative expressions of anger or frustration, such as 'I don't want to do this anymore', 'This is too hard', 'I can't do it'.

Physical frustration: physically negative expressions, such as hitting the box or banging the keys on the table. For example, attempting to pry the box open would not be physical frustration, but banging a fist on the top of the box would be.

Negative facial expressions: negative facial expressions such as frowning or pouting Passive helplessness: Child gives up on task but does not engage in active regulation strategies, may appear sad, angry, or confused.

They also took note of regulatory strategies such as the following:

Bebavioural distraction: doing something other than focusing on the task at hand, including exploring the room, dancing, or singing. Does not count imaginary play. Does not count singing related to the topic at hand (e.g., would NOT include a child singing 'I'm gonna open it, I'm gonna open it'). This is behaviour the child willfully engages in - not a response to a sound in the hallway or the prompt.

Neutral or positive self-directed speech: statements neutral or positive in tone that help the child perform the task (e.g., 'I'm going to try turning it' or 'Hmm it's not this key, maybe it's this one'.)

Seeking support: statements and actions aimed at getting support with the task (e.g., attempting to open the door to find help, calling the experimenter back, calling for parent without whining or sounding helpless). 